\title{
WITHDRAWAL OF INTER-RETINAL FLUID IN DETACHMENT OPERATION BY SIMPLE SUCTION APPARATUS
}

\author{
BY \\ C. J. Blumenthal \\ LONDON
}

ReCently several surgeons at the Moorfields Eye Hospital have been using Weve's operative technique (with minor modifications) for detachment of the retina. In short, this consists of accurate localisation of the hole or holes and the edge of a dialysis by means of a narrow beam of light; and localised surface diathermy by the unipolar method, followed by fine punctures, also unipolar, in the area of surface diathermy. Weve stresses the importance of seeing that the retina surrounding the hole lies in perfect apposition with the choroid at the end of operation. In many, if not in most cases, it is often impossible to remove all the inter-retinal fluid, either by massage or by further punctures, both undesirable practices when carried to excess.

In order to facilitate the removal of fluid, I have tried using a simple suction apparatus which consists of a glass tube with a suction cup at one end, set at the requisite angle, the other end

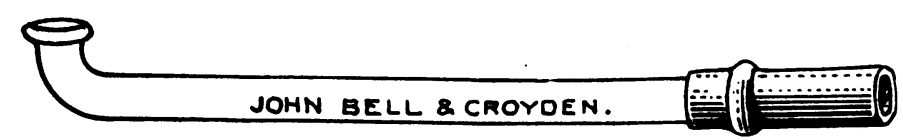

carrying a length of soft rubber tubing. The whole is boiled and set out with the rest of the instruments. A small plug of loose cotton wool may be packed into the distal end of the glass tube, in order to prevent the possibility of a flow of organisms, either air or fluid, borne towards the operation area. This latter is, however, no real danger. Suction is performed by the mouth of the operator, through a thick mask if desired. When the pressure inside the soft tubing is sufficiently reduced its walls collapse, a simple safeguard against obtaining too high a negative pressure.

The element of danger is negligible. Provided the punctures are sufficiently fine (and two or three will suffice), there is no risk whatever of withdrawing vitreous, even when this is fluid. Haemorrhage, which suggests itself at first thought, does not occur.

Frequently I have been surprised at the amount of extra fluid removed after the initial rush following the first punctures. It seems reasonable to suppose that it is better to ensure its removal 
at operation, rather than rely on spontaneous leakage (if this ever occurs) or absorption in the few days immediately following operation.

A view of the fundus on the day after operation bears out this supposition in most cases, and in some it would be difficult to tell, except for the area of coagulation, that there had been a detachment present at all, owing to the entire absence of folds or "ripples" in the retina.

Another possible result of leaving residual fluid behind, even when the coagulated area is flat, is the "floating up" of this area of retina by some unavoidable change of position of the patient's head in the 48 hours immediately after operation.

My thanks are due to those honorary surgeons whose patients I have treated by this technique and to Dr. Browning for his helpful interest. The instrument was made for me by Messrs. John Bell and Croyden.

\title{
A HYDROSTATIC APPROACH TO THE POSTERIOR CHAMBER FOR DIAGNOSTIC AND THERAPEUTIC PURPOSES
}

\author{
BY \\ Professor Dr. A. MOTEGI
}

TAIHOKU, JAPAN

IN my clinic there are three types of patients, whose examination and treatment present considerable difficulty.

1. Patients with poor vision where the anterior segment of the eye is nearly normal, but the fundus invisible.

2. Patients with poor vision, following diseases of the anterior segment, peculiar to the tropics, where the fundus is again invisible. In both types of patients a view of the fundus would be of great value.

3. Panophthalmitis, a relatively common condition in my experience and one for which it is rarely possible to do anything.

To deal with these cases I have devised a technique I described as " Intra-ocular irrigation." 'Through an incised wound of the eyeball I run 0.9 per cent. salt solution or Ringer's solution at body temperature.

The excess drops out of the wound. In infected cases this may be followed by autoserum. If the vitreous is fluid, the eye tends to collapse as it exudes. The irrigation restores the globular form of the eye and enables observation of the interior to be made 